\title{
Sistem Pakar Menentukan Penyakit Hipertensi Pada Ibu Hamil Di RSUD Adjidarmo Rangkas Bitung Provinsi Banten
}

\author{
Robby Rizky ${ }^{[1]}$, Zaenal Hakim ${ }^{[2]}$ \\ Program Studi Sistem Informasi Universitas Mathla'ul Anwar banten [1],[2] \\ robby.rizky@unmabanten.ac.id ${ }^{[1]}$, baduykidul@gmail.com ${ }^{[2]}$
}

\begin{abstract}
Hypertension in pregnancy (preeclampsia and eclampsia) is one of the three main causes of maternal death in addition to bleeding and infection. There are abaout $85 \%$ of preeclampsia occurs in the first pregnancy.Preclampsia occurs in $14 \%$ to $20 \%$ of pregnancies with more than one fetus and $30 \%$ of patients have severe uterine anomalies.The aim of study is to determine the disease in pregnant women due to the difficulty of having a specialist in the field of content in the rangkas district of banten province in the adji darmo regional hospital.the method in this study uses the naive bayes algorithm where the naïve bayes method is proven to be able to solve existing problems that exist that is the difficulty of getting proper treatment in the adji darmo rangkas bitung hospital banten province due to lack of human resources besides lack of resources of his hospital facilities as well as class $C$ facilities is very impossible to check for hypertension in pregnant women so he made it an expert system that can solve these problems so that adji darmo hospital can handle hypertension in pregnant women without the presence of a specialist in obstetrical field.
\end{abstract}

Keywords - expert system,naive bayes, hypertension

Abstrak - Hipertensi Dalam Kehamilan (preklamsia dan eklamsia ) adalah sakahsatu dari tiga penyebab utama kematian ibu di samping pendarahan dan infeksi. Ada sekitar 85\% preeklamsia terjadi pada kehamilan pertama.preklamsia terjadi pada $14 \%$ sampai $20 \%$ kehamilan dengan janin lebih dari satu dan $30 \%$ pasien mengalami anomaly rahim yang berat.Tujuan penelitian ini bertujuan untuk menentukan penyakit pada ibu hamil di karnakan sulitnya memiliki dokter spesialis di bidang kandungan dikabupaten rangkas provinsi banten di RSUD adji darmo.Metode dalampenelitian ini menggunakan algoritma Naïve Bayes dimana metode Naive Bayes ini terbukti dapat memecahkan permasalahan yang ada saat ini dapat di bukrikan dengan penelitian penelitian terdahulu.penelitian ini menggunakan data sampling Data dikumpulkan dengan menggunakan kuesioner dan check list analisis data di lakukan dalam bentuk prosentase.Kesimpulan penelitian ini dapat memecahkan permasalahan yang ada permasalahan yang ada yaitu sulitnya mendapatkan penanganan yang layak di rumah saki adjidarmo rangkas bitung provinsi banten di karnakan sumberdaya manusianya yang kurang selain kurangnya sumber daya manusianya fasilitas rumah sakitnya pun fasilitas kelas $\mathrm{C}$ sangat tidak mungkin untuk mengecek penyakit hipertensi pada ibu hamil maka dari itu dia buatnya sebuah sistem pakar yang dapat memecahkan permasalahan tersebut agar penanganan rumah sakit adji darmo dapat menangani penyakit hipertensi pada ibu hamil tanpa adanya dokter spesialis di bidang kandungan.

Kata Kunci-sistem pakar,nä̈ve bayes,hipertensi

\section{PENDAHULUAN}

Saat ini perkembangan teknologi berkembang dengan sangat cepat. Penerapan teknologi sudah banyak diterapkan dalam berbagai bidang yakni bidang pendidikan bidang kesehatan bidang pertahanan bidang ekonomi bidang politik bidang jasa bidang industri dan berbagai bidang lainnya. Perkembangan teknologi pada bidang ekonomi dapat kita rasakan dengan banyak berdirinya bisnis e-commerce. Dimana pada saat sekarang orangorang dapat memenuhi kebutuhan sehari-hari dengan berbelanja pada aplikasi $e$-commerce. Dengan membuat suatu aplikasi yang mudah di fahami oleh kalangan masyarakat tidakmenutup kemungkinan masyarakat pun sangat antusias untuk menggunakan system pakar ini, system pakar yaitu memindahkan keahlian seseorang terhadap sebuah system sehingga system tersebut menjadi seorang pakar,permasalahan yang terjadi saat ini adalah sulitnya mendapatkan layanan berupa fasilitas yang sangat maksimal di daerah rangkasbitung di karnakan daerat termasuk daerah $3 \mathrm{~T}$ daerah tertinggal dan sulitnya mendapatkan tenaga dokter spesialis di bidang penyakit hipertensi.oleh sebab itu permasalahan yang ada harus segera di atasi,agar masyarakat dapat merasakan rasa nyaman dan yang memiliki penyakit hipertensi segera teratasi,"Sistemkomputermempunyaikeunggulan sebagai tempat penyimpanan data dan instruksi dalam jumlah yang relatif besar, selain itu komputer dapat diprogram sesuai kebutuhan sehingga dapat melaksanakan pekerjaan tertentu secara terus dan konsisten.

Berbagai penelitian sebelumnya yang membahasa tentang bahayanya penyakit hipertensi "penyakit hipertensi di sebabkan dari gaya hidup yang tidak sehat dari pola makanan dan olah raga yang tidak teratur,tidak dapat mengendalikan stress dan adanya kebiasaan merokok",[1], "di ketahui juga hubungan diabetes mellitus dengan hipertensi sangat kuat karena ada beberapa criteria yang sering ada pasa pasiean hipertensi yaitu peningkatan 
tekanan darah,obesitas ,dislipedemia,dan peningkatan glukosa darah",[2],"diabetes mellitus dan lain lain penderita hipertensi sangat heterogen hal ini membuktikan bahwa hipertensi bagaikan mozaik,di derita oleh orang banyak yang dating dari beberapa sub golongan beresiko di dalam masyarakat ,hipertensi di pengaruhi oleh factor resiko ganda,baik yang bersifat endogen ,eksogen seperti rook stress dan lain lain",[3] dari permasalahan yang sudah di ungkap pada penelitian terkait tersebut,di butuhkan suatu metode yang dapat memecahkan permahsalahan hipertensi tersebut sehingga perancangan dan pembuatan system pakar ini dapat terwujud.

Metode naive bayes dapat memecahkan persoalah tentang penyakit hipertensi di karnakan metode naïve bayes, metode yang berdasarkan aturan berupa rule base diantaranya "system prediksi penyakit kanker serviks menggunakan naïve bayes ",[4], "system pakar deteksi penyakit hipertensi pada rsud gorontalo ",[5], "factor factor yang berhubungan dengan penyakit hipertensi dengan pendekatan naïve bayes",[6],"sters terhadap kejadian komplikasi hipertensi pada pasien hipertensi",[7],"system pendukung keputusan diagnosis dini penyakit hipertensi dengan metode naïve bayes",[8]

Dengan perhitungan metode naive bayes akan menghasilkan informasi tentang insesitas deteksi dini penyakit hipertensi yang nanti nya akan di terapkan di sebuah system computer untuk nantinya di ajukan acuan untuk pencegahan penyakit hipertensi untuk kalangan masyarakat rangkas bitung provinsi banten pada ibu hamil.

Penelitian ini wawancara langsung dengan para pakar di bidang kedokteran khususnya penyakit hipertensi agar mendapatkan data terkait penyakit hipertensi, permasalahan yang ada yaitu sulitnya alat pendeteksi di bidang kedokteran di rumahsakit rangkas bitung dan sulitnya mendapatkan tenaga medis di bidang penyakit hipertensi agar kedepanya masyarakat awam pun dapat memahami pencegahan penyakit hipertensi yang selama ini menghantui warga masyarakat rangkas bitung di wilayah provinsi banten yang selama ini selalu mendapatkan rujukan ke rumah sakit kota.

Berdasarkan permasalahan yang terjadi dengan metode naive bayes di terapkan untuk mendeteksi penyakit hipertensi ,yang bertujuan untuk menyempurnakan aplikasi system pakar ini yang akan di bangun kedepanya.

\section{METODOLOGI PENELITIAN}

\section{A. Metode Pengumpulan Data}

Pada penelitian ini,dalam pengumpulan data menerapkan 3 metode, yang pertaman metode wawancara,dimana peneliti mengumpulkan data dengan cata bertanya kepada para pakar di bidangnya secara langsung. Metode kedua yang peneliti lakukan adalah melakukan pengamatan secara langsung terhadap objek penelitian, dengan cara melakukan pencatatan secara langsung terhadap kejadian kejadian yang sedang di teliti. Dan metode terakhir adalah studi pustaka pengumpulan data yang di lakukan dengan membaca buku-buku literature,jurnal,internet,majalah,dan penelitian terdahulu yang berkaitan dengan penelitian yang sedang di lakukan.

\section{B. Metode Analisis Data}

Metode Analisis data yang peneliti lakukan adalah menganalisa data tentang penyakit yang berkaitan dengan penyakit hipertensi pada ibu hamil dan bagaimana cara penanganan penyakit tersebut agar kedepanya data tersebut dapat di aplikasikan ke dalam sebuah system.

\section{Tahapan Penelitian}

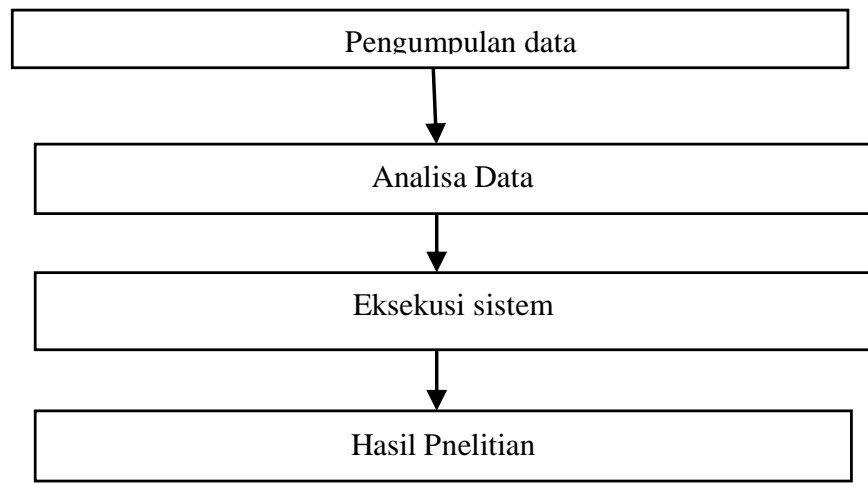

Gambar I Tahapan Penelitian Sumber :(Hasil Penelitian 2018)

Keterangan :

1) Pengumpulan data : istilah asing teknik pengumpulan data adalah proses formal menggunakan teknik seperti wawancara dan daftar pertanyaan kuesioner untuk mengumpulkan fakta tentang sistem,kebutuhan dan pilihan.

2) Analisa data :analisa data dalam penelitian ini yaitu suatu kegiatan yang di lakukan untuk mengubah data hasil dari penelitian menjadi sebuah informasi baru yang dapat di gunakan dalam sebuah kesimpulan data yang sudah di dapat nanti akan di hitung menggunakan algoritma naïve bayes alas an menggunakan algoritma naïve bayes agar akurat perhitungan nya.

3) Eksekusi sistem : tahapan ini adalah tahapan memasukan hasil dari pengolahan data tersebut yang nanti akan di tuangkan ke dalam sistem aplikasi .

4) Hasil penelitian merupakan hasil yang nantinya di harapkan dalam penelitian ini.

\section{HASIL DAN PEMBAHASAN}

\section{A. Prosedur Sistem Berjalan}

Pada proses ini pasien mengunjungi ke RSUD lalu pasien di periksa oleh dokter umum, permaslahan pada ibu hamil yaitu sulitnya dokter umum menganalisa penyakit pada ibu hamil di karnakan dokter umum adalah bukan dokter spesialis untuk menangani ibu hamil, pasien selalu di rujuk ke dokter spesialis agar mendapatkan hasil yang lebih akurat permasalahan berikutnya adalah jarak rangkas ke tempat dokter spesialis sangan jauh sehingga menhabiskan banyak waktu untuk menempuh perjalanan.

\section{B. Identifikasi Permasalahan}

Di dalam pelayanan rumah sakit adji darmo rangkasbitung terdapat permasalahan yaitu sulitnya memiliki fasilitas peralatan rumah sakit yang memadai dan sulitnya memiliki dokter spesialis 
di bidang yang di butuhkan pada penderita hipertensi hususunya ibu hamil,mengakibatkan pasien selalu mendapatkan rujukan dari dokter umum di rumah sakit umum tersebut, permasalahan lain adalah jauhnya rumah sakit rujukan tersebut .

Dalam persoalan tersebut maka mengakibatkan persoalan lain yaitu :

1) Pasien enggan pergi ke rumah sakit harapan kita di karnakan jarak yang sangat jauh dan biaya angutan umum yang sangan mahal.

2) Di karnakan pasien enggan pergi ke rumah sakit rujukan maka penyakit hipertensi tersebut tidak terobati dan membahayakan kepada diri si pasien dan kandunganya tersebut.

Tabel 1. Probabilitas Penyakit

\begin{tabular}{|l|l|l|l|l|}
\hline Kode & Penyakit & Jm & total & $\begin{array}{l}\text { Probabilitas } \\
\text { penyakit }\end{array}$ \\
\hline P01 & $\begin{array}{l}\text { Hipertensi } \\
\text { gestasional }\end{array}$ & 26 & 81 & $\begin{array}{l}0.320987654 \\
32099\end{array}$ \\
\hline P02 & $\begin{array}{l}\text { Hipertensi } \\
\text { preklampsia }\end{array}$ & 47 & 81 & $\begin{array}{l}0.580246913 \\
58025\end{array}$ \\
\hline P03 & $\begin{array}{l}\text { Hipertensi } \\
\text { eklamsia }\end{array}$ & 8 & 81 & $\begin{array}{l}0.098765432 \\
098765\end{array}$ \\
\hline
\end{tabular}

Menghitung probabilitas penyakit

P $($ Penggunaan penyakit $)=$ Hipertensi Gestasional

$\mathrm{P}($ Penggunaan penyakit $)=$ Hipertensi Preeklampsia

$\mathrm{P}($ Penggunaan penyakit $)=$ Hipertensi Eklamsia

$\mathrm{P}($ Penggunaan penyakit $=$ hipertensi gestasional $)$

$=$ jumlah penyakit hipertensi gestasional / jumlah penyakit =hipertensi gestasional + jumlah penyakit preeklampsia + jumlah penyakit eklamsia.

$=26 / 81=0,32$

1. Probabilitas Gejala

a) $\quad$ P $($ gejala $=$ darah tinggi sebelum hamil $\mid$ penyakit $=$ hipertensi gestasional $)=1+($ jumlah gejala $=$ darah tinggi sebelum hamil dan penyakit $=$ hipertensi gestasional $) /($ jumlah penyakit $=$ hipertensi gestasional $+2)$

$=(1+7) /(26=2)=0,29$

b) $\quad$ P $($ gejala $=$ darah tinggi sebelum hamil $\mid=$ hipertensi praeklampsia )

$=1+($ jumlah gejala $=$ darah tinggi sebelum hamil dan penyakit preeklampsia $) /($ jumlah penyakit $=$ hipertensi preeklampsia +2$)$

$=(1+3) /(47+2)=0,08$.

c) $\mathrm{P}$ ( gejala = darah tinggi sebelum hamil $\mid=$ hipertensi eklamsia $)=1+($ jumlah gejala $=$ darah tinggi sebelum hamil dan penyakit eklampsia )/ (jumlah penyakit = hipertensi elampsia +2$)$

$$
=(1+1) /(8+2)=0,2
$$

2. Diagnosis

a) $\quad \mathrm{P}($ Gejala $=$ darah tinggi sebelum hamil $\mid \mathrm{x})=(\mathrm{P}($ Jumlah gejala $=$ darah tinggi sebelum hamil $\mid$ penyakit $=$ hipertensi gestasional $)$ x P ( Gejala = darah tinggi pada kehamilan sebelumnya $\mid$ penyakit $=$ hipertensi gestasioanal $)) \times \mathrm{P}($ Penyakit $=$ hipertensi gestasional $)$ $=0,29 \times 0,32 \times 0,32=0,029$

b) $\mathrm{P}($ Gejala $=$ darah tinggi sebelum hamil $\mid \mathrm{x})=(\mathrm{P}($ Jumlah gejala $=$ darah tinggi sebelum hamil $\mid$ penyakit $=$ hipertensi gestasional $)$ x P ( Gejala = darah tinggi pada kehamilan sebelumnya $\mid$ penyakit $=$ hipertensi praeklampsia )) $\mathrm{x}$ P ( Penyakit $=$ hipertensi preeklampsia )

$=0,8 \times 0,06 \times 0,57=0,0028$

c) $\mathrm{P}($ Gejala = darah tinggi sebelum hamil $\mid \mathrm{x})=(\mathrm{P}($ Jumlah gejala $=$ darah tinggi sebelum hamil $\mid$ penyakit $=$ hipertensi gestasional $)$ x P ( Gejala $=$ darah tinggi pada kehamilan sebelumnya $\mid$ penyakit $=$ hipertensi eklampsia) $)$ x P $($ Penyakit $=$ hipertensi eklamsia $)$

$$
=0,02 \times 0,3 \times 0,098=0,059
$$

3. Presentase Diagnosis

Rumus : Nilai Probabilitas / Total Probabilitas

a) Nilai presentase hipertensi gestasional

Nilai probabilitas $=(0,029 / 0,0385) \times 100$

$=0,774 \times 100$

$=77 \%$

b) Nilai probabilitas $=(0,0028 / 0,0385) \times 100=0,072 \times$ 100

$=7,2 \%$

c) Nilai probabilitas $=(0,0059 / 0,0385) \times 100$

$=0,1532 \times 100$

$=15,32 \%$

Tabel 2. Rule Naïve Bayes

\begin{tabular}{|c|c|c|c|c|}
\hline Id rule & $\begin{array}{c}\text { Kode } \\
\text { gejala }\end{array}$ & $\begin{array}{c}\text { Kode } \\
\text { penyakit }\end{array}$ & Ya & Tdk \\
\hline 121 & G01 & P01 & 0.29 & 0.71 \\
\hline 122 & G01 & P02 & 0.08 & 0.92 \\
\hline 123 & G01 & P03 & 0.2 & 0.8 \\
\hline 124 & G02 & P01 & 0.32 & 0.68 \\
\hline 125 & G02 & P02 & 0.06 & 0.94 \\
\hline 126 & G02 & P03 & 0.3 & 0.7 \\
\hline 127 & G03 & P01 & 0.5 & 0.5 \\
\hline 128 & G03 & P02 & 0.22 & 0.78 \\
\hline 129 & G03 & P03 & 0.3 & 0.7 \\
\hline 130 & G04 & P01 & 0.36 & 0.64 \\
\hline 131 & G04 & P02 & 0.08 & 0.92 \\
\hline 132 & G04 & P03 & 0.2 & 0.8 \\
\hline 133 & G05 & P01 & 0.39 & 0.61 \\
\hline 134 & G05 & P02 & 0.12 & 0.88 \\
\hline 135 & G05 & P03 & 0.2 & 0.8 \\
\hline 136 & G06 & P01 & 0.32 & 0.68 \\
\hline 137 & G06 & P02 & 0.08 & 0.92 \\
\hline 138 & G06 & P03 & 0.2 & 0.8 \\
\hline
\end{tabular}




\begin{tabular}{|c|c|c|c|c|}
\hline Id rule & $\begin{array}{c}\text { Kode } \\
\text { gejala }\end{array}$ & $\begin{array}{c}\text { Kode } \\
\text { penyakit }\end{array}$ & Ya & Tdk \\
\hline 139 & $\mathrm{G} 07$ & $\mathrm{P} 01$ & 0.25 & 0.75 \\
\hline & $\mathrm{T}$ & $\mathrm{P}$ & 0.14 & 0
\end{tabular}$\quad \quad$\begin{tabular}{|c|c|c|c|c|} 
Id rule & $\begin{array}{c}\text { Kode } \\
\text { gejala }\end{array}$ & $\begin{array}{c}\text { Kode } \\
\text { penyakit }\end{array}$ & Ya & Tdk \\
\hline
\end{tabular}

Langkah selanjutnya jika table rule sudah di buat, kode gejala dan lain lain yang akan di masukan ke dalam algoritma sistem pakar sehingga aplikasi system pakar dapat di bangun sedemikian rupa sesuai dengan yang di harapkan.

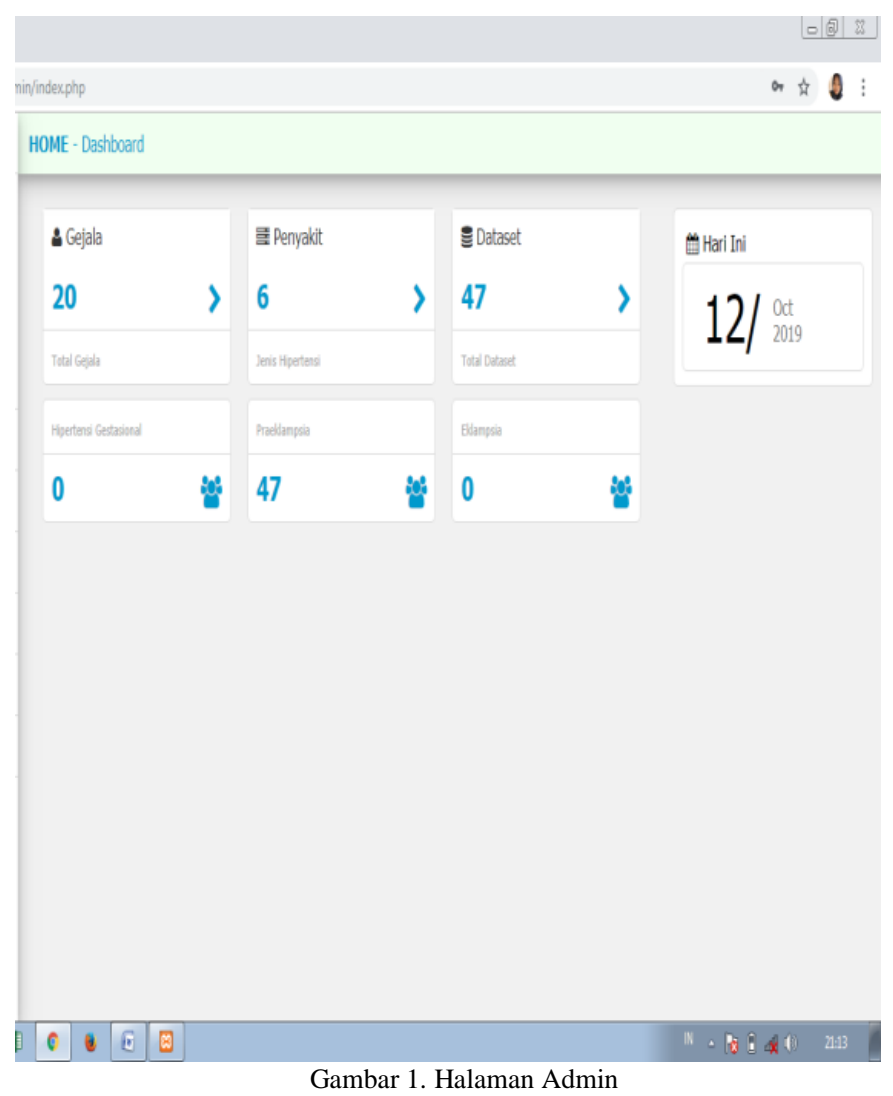

Keterangan : di dalam data master terdapat data penyakit dan data gejala ini adalah data penyakit,di sini admin akan menginputkan data pasien yang terkena penyakit tersebut 


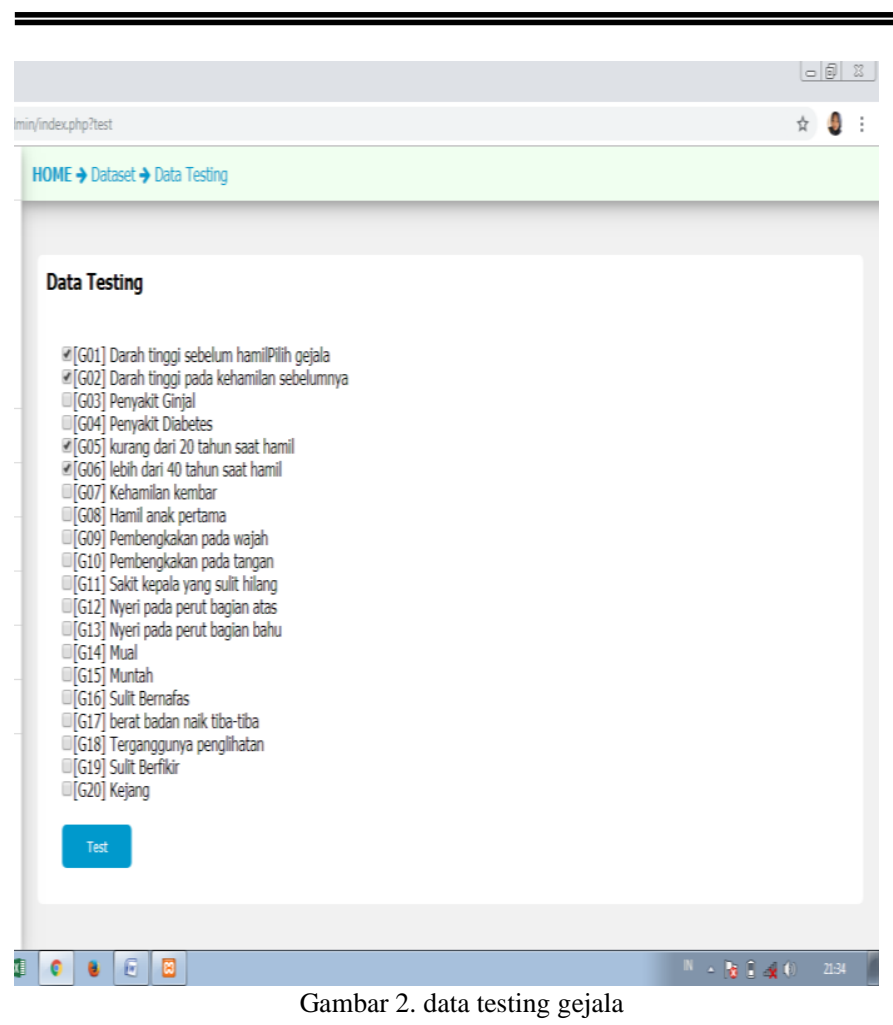

Keterangan : pada menu ini memilih keluhan gejala yang di derita oleh si pasien

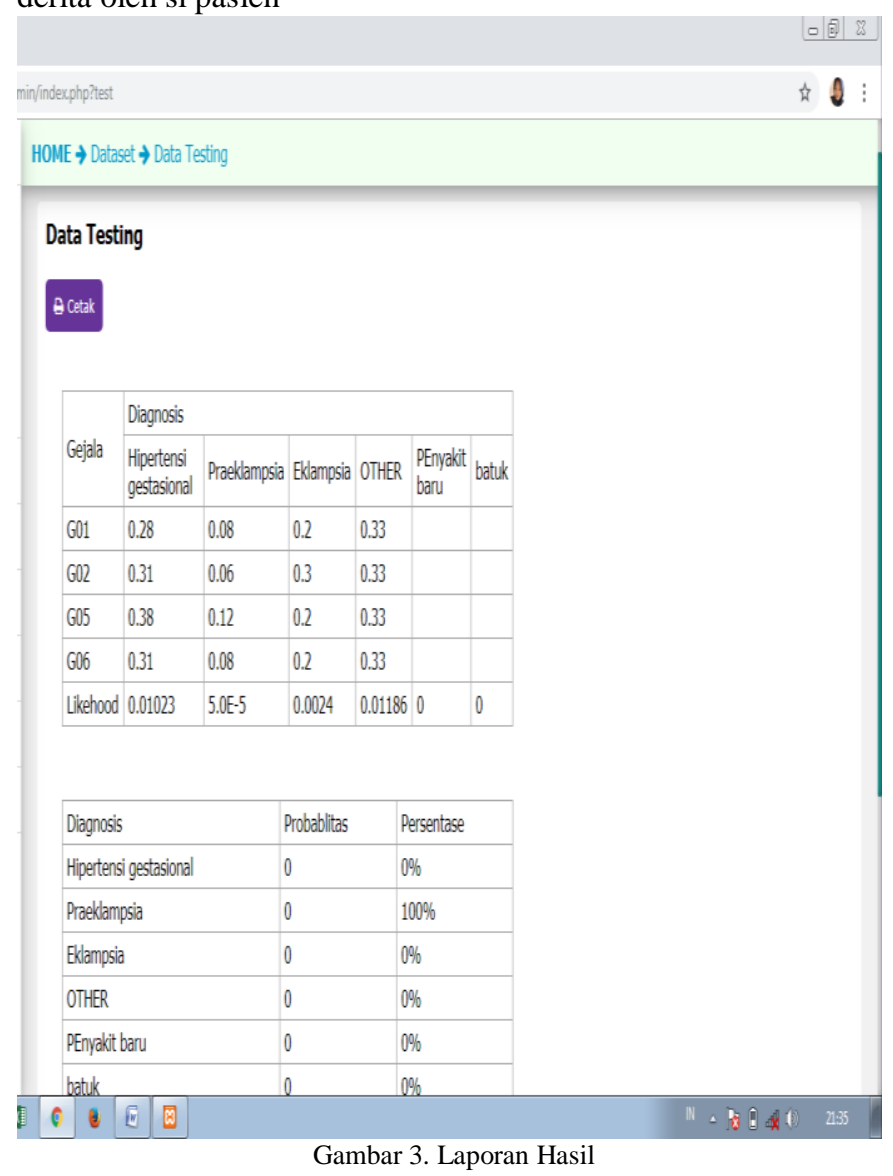

Keterangan : di dalam gambar ini terdapat laporan hasil dari pengolah yang tadi di masukan segala macam gejala penyakit yang di keluhkan pasien

\section{PENUTUP}

Berdasarkan hasil pengujian sistem aplikasi sistem pakarinimakadi per oleh kesimpulan sebagai berikut :

1. Dapat mendiagnosis penyakit hipertensi pada ibu hamil.

2. Dapat menentukan presentase penyakit hipertensi secara akurat

3. Memudahkan penanganan dokter umum untuk menagani penyakit hipertensi pada ibu hamil

\section{DAFTAR PUSTAKA}

[1] M. Suoth et al., "Hubungan Gaya Hidup Dengan Kejadian Hipertensi Di Puskesmas Kolongan Kecamatan Kalawat Kabupaten Minahasa Utara," J. Keperawatan, vol. 2, no. 1, 2014.

[2] R. Alfian, Y. Susanto, and S. Khadizah, "Kualitas Hidup Pasien Hipertensi Dengan Penyakit Penyerta Di Poli Jantung RSUD Ratu Zalecha Martapura," J. Pharmascience, vol. 4, no. 2, pp. 210-218, 2017.

[3] D. R. Puspitasari, M. T. Setyabudi, and A. Rohmani, "Hubungan Usia, Graviditas dan Indeks Massa Tubuh dengan Kejadian Hipertensi Dalam Kehamilan," J. Kedokt. Muhammadiyah, vol. 2, no. 1, pp. 29-33, 2015.

[4] T. Praningki and I. Budi, "Sistem Prediksi Penyakit Kanker Serviks Menggunakan CART, Naive Bayes, dan k-NN," Creat. Inf. Technol. J., vol. 4 , no. 2 , p. 83, 2018.

[5] I. Candra Dewi, A. Andy Soebroto, and M. Tanzil Furqon, "Sistem Pakar Diagnosa Penyakit Sapi Potong Dengan Metode Naive Bayes," $J$. Enviromental Eng. Sustain. Technol., vol. 2, no. 2, pp. 72-78, 2015.

[6] S. C. Qudsiah, H. S. Djarot, and S. Nurjanah, "Jurnal Kebidanan.," J. Kebidanan, vol. 2, no. 1, pp. 127-134, 2018.

[7] D. Prawesti, "Stres pada penyakit terhadap kejadian komplikasi Hipertensi pada pasien Hipertensi," J. Stikes, vol. 5, no. 2, pp. 121-132, 2012.

[8] N. Radjamuda and A. Montolalu, "Faktor-Faktor Risiko Yang Berhubungan Dengan Kejadian Hipertensi Pada Ibu Hamil Di Poli Klinik Obs-Gin Rumah Sakit Jiwa Prof. Dr. V. L. Ratumbuysang Kota Manado," J. Ilm. Bidan, vol. 2, no. 1, pp. 33-40, 2014. 